\title{
Loading and Release Profile Assay of Carbonated Hydroxyapatite Incorporated with Propolis as Bone Graft Material
}

\author{
Indi Kusumawati ${ }^{1}$, Suryono $^{2 *}$, Ahmad Syaify ${ }^{2}$ \\ ${ }^{1}$ Clinical Dentistry Program, Faculty of Dentistry, Universitas Gadjah Mada, Yogyakarta, Indonesia \\ ${ }^{2}$ Periodontology Department, Faculty of Dentistry, Universitas Gadjah Mada, Yogyakarta, Indonesia
}

\begin{abstract}
Periodontitis can lead to the destruction of the alveolar bone. The loss of the alveolar bone can be treated using carbonated hydroxyapatite $(\mathrm{CHA})$ as a bone graft material. However, $\mathrm{CHA}$ is an alloplastic graft whose primary function is to act as a scaffold, but it is unable to stimulate the process of bone regeneration. Carbonated hydroxyapatite is an avascular synthetic material, which will increase the risk of bacterial adhesion on site that can lead to unsuccessful periodontal therapy. The incorporation of propolis into CHA is expected to add antibacterial capability into CHA. Besides its antibacterial property, propolis also has a bone regenerating effect. Mixing CHA with propolis needs to consider the process of loading the active ingredients into the carrier. The release of propolis is expected to occur gradually over a lengthy period. The purpose of this study was to analyze the loading and releasing assay for propolis incorporated with CHA. A propolis solution of 5\%, 7.5\%, and $10 \%$ was each incorporated into $10 \mathrm{mg}$ of CHA. The loading percentage and releasing assay of propolis were measured. The absorbance reading was done at $289 \mathrm{~nm}$ using a UV-vis. It was shown that a $10 \%$ propolis solution had the highest loading percentage $(32.08 \%)$, while the $5 \%$ propolis solution had the smallest loading percentage $(10.63 \%)$. The propolis releasing profiles in all concentration groups were similar. The difference in propolis concentration incorporated with CHA affected the loading percentage but did not affect the propolis releasing assay.
\end{abstract}

Keywords: Carbonated hydroxyapatite; Propolis; Loading; Release

\section{INTRODUCTION}

Periodontitis is a chronic inflammation of the periodontal tissue that can lead to the destruction of the alveolar bone (Carranzza et al., 2012). The destruction of the alveolar bone can be treated using carbonated hydroxyapatite (CHA) as bone graft material. Carbonated hydroxyapatite is an alloplastic material that is biocompatible with the alveolar bone and possesses osteoconductive properties (Ana et al., 2010). It is a synthetic material that functions as a scaffold to maintain space but is unable to stimulate bone regeneration (Bashutski and Wang, 2009). Alloplastic materials are not vascularized because they are synthetic, which later leads to bacterial adhesion. Hence, adding an antibacterial agent is suggested to prevent such adhesion (Filho et al., 2014).

As widely known, the use of antibiotics could lead to bacterial resistance. This fact warrants the development of natural products, such as propolis, to act as alternatives to antibacterial agents. Propolis is a natural resin substance produced by bees to protect the hive. The antibacterial properties of propolis are contributed by its phenol content that causes functional and structural changes in bacteria, such

\footnotetext{
*Corresponding author : Suryono

Email : suryonodent@mail.ugm.ac.id
}

as cytoplasm membrane damage, inhibits nucleic acid synthesis, and inhibits the formation of biofilm (Scatolini et al., 2018). Propolis also possesses the ability to regenerate bone by increasing osteoblast activity and decreasing osteoclast activity (Zohery et al., 2018).

An in vivo study showed that $10 \%$ propolis gel could stimulate the healing process of gingivitis on experimental animals by decreasing PMN cells, increasing the osteoblast count, and promoting angiogenesis (Suryono et al., 2017). Another study showed that periodontal therapy using 10\% Brazilian propolis was effective in treating gingivitis and chronic periodontitis (Cairo et al., 2006). A study by Samad et al. (2017) proves that mouthwash containing 5\%, 7.5\%, and $10 \%$ propolis was effective in reducing gram-negative anaerobic bacteria.

Incorporation of carbonated hydroxyapatite with propolis needs to consider the loading process of the active ingredient into the carrier; in this case, it is the bone graft. The releasing profile of propolis is expected to happen gradually over a relatively long time (Bara et al., 2018). The purpose of this study was to analyze the incorporation of carbonated hydroxyapatite with propolis by measuring the loading and releasing profile of propolis. 


\section{METHODOLOGY \\ Materials \\ Preparation of Carbonated Hydroxyapatite Incorporated with Propolis \\ This study used a carbonated} hydroxyapatite block from Gama-CHA ${ }^{\circledR}$ (Yogyakarta, Indonesia). The shape of carbonated hydroxyapatite used was cylindrical with a diameter of $6 \mathrm{~mm}$, a length of $10 \mathrm{~mm}$, and a weight of $70 \mathrm{mg}$. The carbonated hydroxyapatite block was cut into $10 \mathrm{mg}$ each. The propolis used in this study was from Propolis Brazilian ${ }^{\circledR}$ (Minas GeraisBrazil, distributed by Nusa Mega Persada). The propolis was diluted using the gradual dilution technique with double distilled water to obtain concentrations of $5 \%, 7.5 \%$, and $10 \%$ (group A, group $\mathrm{B}$, and group $\mathrm{C}$, respectively). The carbonated hydroxyapatite was immersed into the propolis solution for $24 \mathrm{~h}$ at room temperature. The samples were replicated six times for each concentration.

\section{Methods}

\section{Loading Assay}

After immersion for $24 \mathrm{~h}$, the remaining propolis solution was put into the UV-vis spectrophotometer cuvette to measure the absorbance value. As comparison data, propolis solution of $5 \%, 7.5 \%$, and $10 \%$ that were not involved in the immersing process were put into another cuvette for absorbance value measurements. Double-distilled water was used as a blank solution. Absorbance readings were made at $289 \mathrm{~nm}$ using the UV-vis spectrophotometer (UV-1800, Shimadzu, Japan). The calculation of loading percentage was done to determine the amount of absorbed propolis into the carbonated hydroxyapatite, which done by measuring the absorbance value before and after immersion. The calculation used the following equation provided by a previous study of Madhumathi and Kumar (2014) and Ardhani et al., (2016):

$$
\frac{(A-B)}{A} \times 100 \%
$$

A: The absorbance of propolis before incorporation with carbonated hydroxyapatite; B: The absorbance of propolis after incorporation with carbonated hydroxyapatite

\section{Release Profile Assay}

The carbonated hydroxyapatite, which already was immersed with propolis solution, was dried out using an incubator at $37{ }^{\circ} \mathrm{C}$ while covered with filter paper. Once dried out, the carbonated hydroxyapatite was put into PBS solution ( $\mathrm{pH} 7.4)$ for one h. The solution was then centrifuged using the centrifuge (5415 D, Eppendorf) at $2000 \mathrm{rpm}$ for $5 \mathrm{~min}$. After that, the PBS solution was put into a UV-vis spectrophotometer cuvette while carbonated hydroxyapatite specimen was left in the microcentrifuge tube. Fresh PBS solution was added into the microcentrifuge tube together with carbonated hydroxyapatite. The absorbance reading for the PBS solution was done using a UVvis spectrophotometer (UV-1800, Shimadzu, Japan) at $289 \mathrm{~nm}$. The steps were repeated at $3 \mathrm{~h}$, $6 \mathrm{~h}, 24 \mathrm{~h}, 48 \mathrm{~h}$, and $72 \mathrm{~h}$ interval. The absorbance reading result was compared with the time interval to measure the release profile. The calculation of the propolis releasing profile used the percentage of release, which was obtained from the same equation as that for propolis loading.

\section{Statistical Analysis}

The data obtained were analyzed using a one way ANOVA with a significance level of .05. The calculation was continued with the least significant difference (LSD) post-hoc test.

\section{RESULTS AND DISCUSSION Loading Assay}

The measurement of the propolis loading percentage was replicated six times for each concentration. Figure 1 shows descriptive data regarding the loading percentage. The highest loading percentage was found in group C (32.08\%), and the lowest loading percentage was found in group A (10.63\%).

The statistical analysis showed that there was a significant difference between groups regarding the loading percentage $(P<.05)$. The post-hoc test analysis showed that there were significant differences between all tested groups.

The incorporation method used in this study was the immersion method. The immersion process, followed by incubation for a specific time, is one of the easiest contact methods between antibacterial agents and the bone graft material (Anagnostakos and Schrder, 2012). In this method, the porosity and surface area of the bone graft can affect the absorption of antibacterial agents (Dashti et al., 2010). The bond between the carbonated hydroxyapatite and the propolis is attributed to the gelatinous composition within the bone graft material used in this study. The hydrophilic cluster in the gelatin is a polar amino acid group that will be attracted to a fluid under dry conditions (Peña et al., 2010).

The post-hoc test showed that the highest propolis loading percentage $(32.08 \%)$ was found in the $10 \%$ group (group C), while the lowest 


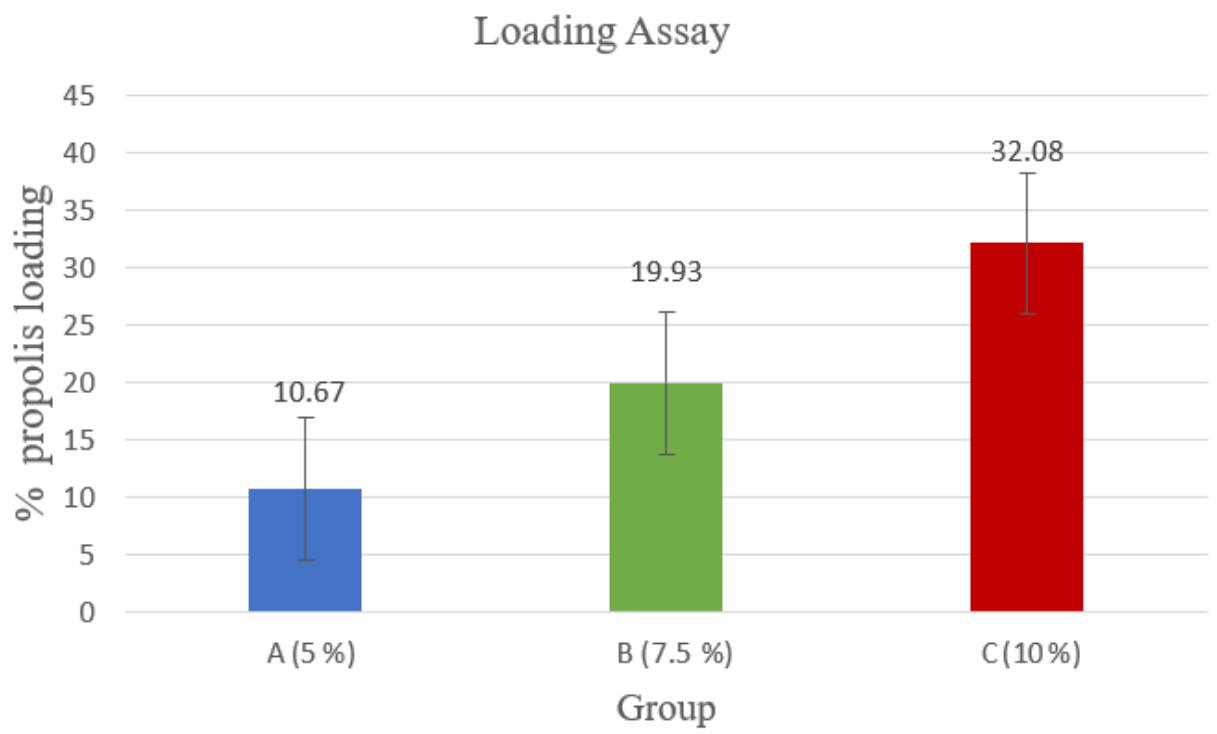

Figure 1. Propolis Loading Percentage

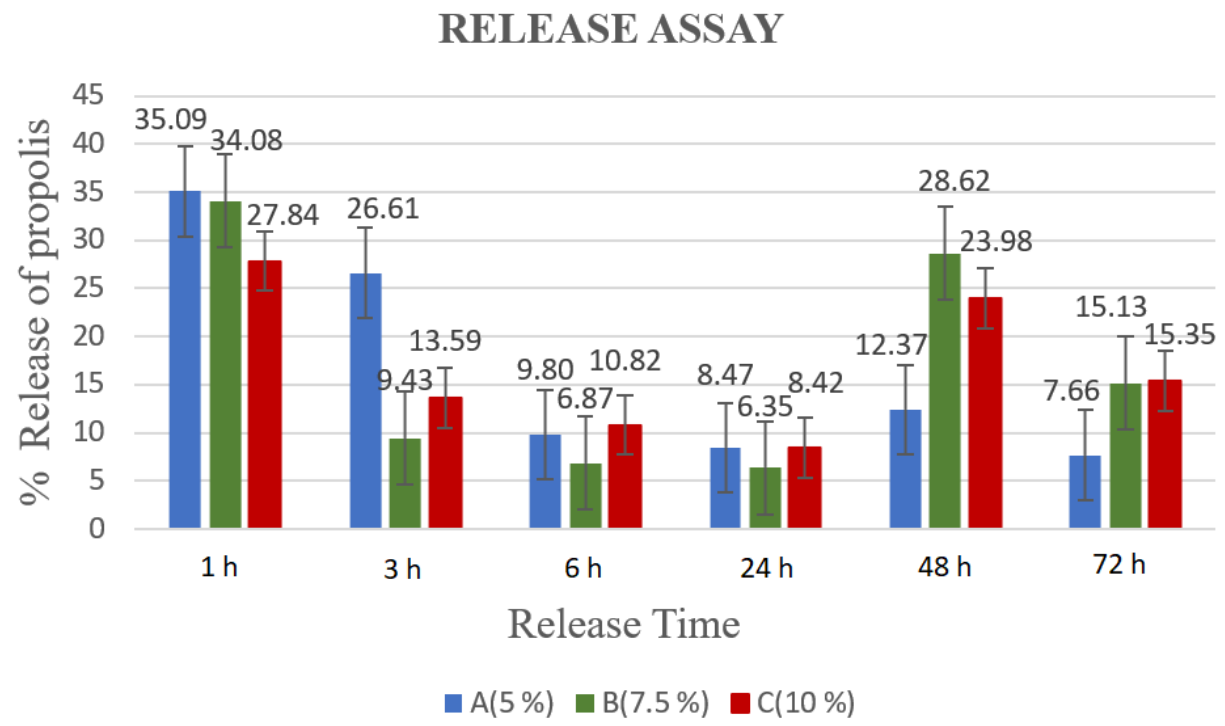

Figure 2. Percentage Propolis Release

propolis loading percentage (10.63\%) was found in the $5 \%$ group (group A). This result meant that the $10 \%$ propolis was the most absorbed concentration compared with $5 \%$ and $7.5 \%$ propolis. The lower the concentration of propolis, the higher the double-distilled water content, and this could lead to the dissolution of the carbonated hydroxyapatite. In addition, this could cause a reduction in the surface area of the bone graft material and result in a decline in the level of propolis absorbance. Therefore, the lower the concentration of propolis, the greater is the reduction in the loading percentage. This result is consistent with the previous theory that the bone graft surface area would affect the absorbance level of antibacterial agents, which in this study is propolis (Dashti et al., 2010).

\section{Release Profile Assay}

Figure 2 shows the mean value of propolis release per group per time interval. The release rate of all groups was at the highest in the first hour. All tested groups had a gradual decrease in the release rate until the first $24 \mathrm{~h}$. The next 


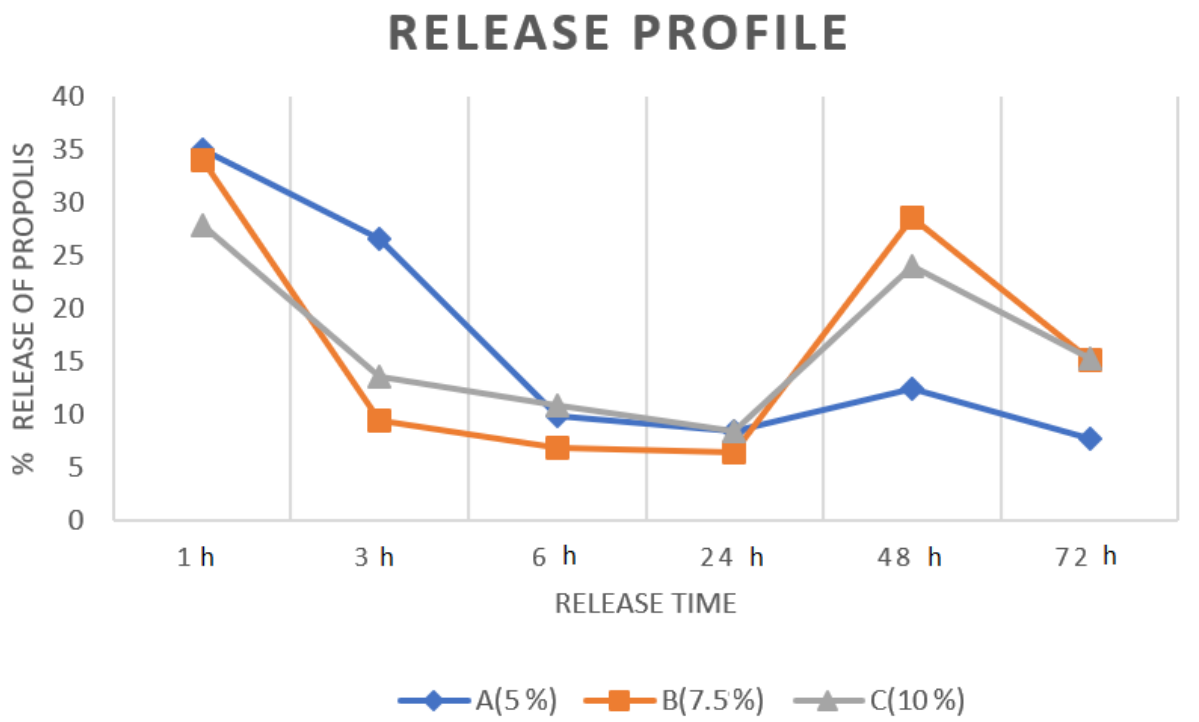

Figure 3. Propolis Release Profile

measuring times were $48 \mathrm{~h}$ and $72 \mathrm{~h}$, which showed higher release rates because the interval times were longer than the first $24 \mathrm{~h}$.

The statistical analysis using a one way ANOVA shows that there was no significant difference between all groups regarding the percentage of propolis released $(P>.05)$. This result suggests that differences in the propolis concentration did not affect the percentage that was released.

Figure 3 shows the percentage of propolis released into the PBS solution after incubation during several time points. The lines intersect at several observation times. The release profiles among all groups are quite similar. The highest release percentage was found in the first hour, and then gradually decreased until the first $24 \mathrm{~h}$. The release of propolis was still detected until $72 \mathrm{~h}$.

The propolis release assay was done at $1 \mathrm{~h}$, $3 \mathrm{~h}, 6 \mathrm{~h}, 24 \mathrm{~h}, 48 \mathrm{~h}$, and $72 \mathrm{~h}$. The results indicated that the degradation of carbonated hydroxyapatite into the PBS solution was highest during the first hour and was compatible with the findings of other studies (Ardhani et al., 2016). The high release of a substance at the beginning of the observation time, also known as the "burst release," was beneficial to eradicate bacteria locally post-operation (Phaechamud and Darunkaisorn, 2016).

The propolis release profile shows an initial burst release followed by a prolonged release for $72 \mathrm{~h}$. The burst release occurs due to the desorption of drug molecules that are loosely bound to the surface, followed by the dissolution of
CHA crystals. (Madhumathi and Kumar, 2014). This study showed that propolis release occurred more in the first $24 \mathrm{~h}$. This type of release is similar to the one in the study by Dashti et al. (2010), which found that in a static environment, such as a PBS solution, most drugs were released within $24 \mathrm{~h}$.

\section{CONCLUSION}

The data from this study imply that the differences in propolis concentration affected the loading percentage of propolis. A higher concentration of propolis would result in a higher propolis loading percentage, which means there is more propolis absorbed into the carbonated hydroxyapatite. On the other hand, the differences in propolis concentration did not affect the percentage released.

This is a pilot study on carbonated hydroxyapatite incorporated with propolis. Thus, further research is needed to investigate the absolute values to load and release the bonds between the carbonated hydroxyapatite and propolis solution, and the time limit for propolis release over a longer period.

\section{ACKNOWLEDGEMENT}

This study was funded by grant Hibah Penelitian Dana Masyarakat Berbasis Luaran (Outcome Based) Faculty of Dentistry Universitas Gadjah Mada, the Republic of Indonesia, in the fiscal year 2019 under contract No. 4349/UN1/FKG1/Set.KG1/PT/2019. 


\section{REFERENCES}

Ana, I.D., Matsuya, S. \& Ishikawa, K. 2010. 'Engineering of carbonate apatite bone substitute based on compositiontransformation of gypsum and calcium hydroxide', Engineering, 02(05), 344-352.

Anagnostakos, K. \& Schrder, K. 2012. 'Antibioticimpregnated bone grafts in orthopaedic and trauma surgery: A systematic review of the literature'. International Journal of Biomaterials,

Ardhani, R., Setyaningsih, Hafiyyah, O.A. \& Ana, I.D. 2016. 'Preparation of carbonated apatite membrane as metronidazole delivery system for periodontal application'. Key Engineering Materials, 696, 250-258.

Bara, J.J. 2018. 'A doxycycline inducible, adenoviral bone morphogenetic protein-2 gene delivery system to bone'. Journal of Tissue Engineering and Regenerative Medicine, 12(1), e106-e118.

Bashutski, J.D. \& Wang, H.L. 2009. 'Periodontal and endodontic regeneration'. Journal of Endodontics, 35(3), 321-328.

Cairo, R., Tomaz, R., Santos, W., Rago, S. \& Rodrigues, V. 2006. 'Periodontitis treatment with Brazilian green propolis gel'. Pharmacology Online, 3(May), 336-341. http://pharmacologyonline.silae.it/files/ar chives/2006/vol3/026.Santos.pdf

Newman, M. G., Takei, H., Klokkevold, P. R. \& Carranza, F.A. 2012. Carranza's Clinical Periodontologi (11th ed.), Saunders Elsevier, St Louis Missouri.

Dashti, A., et al., (2010). 'In vitro antibacterial efficacy of tetracycline hydrochloride adsorbed onto Bio-Oss $®$ bone graft'. Journal of Biomedical Materials Research - Part B Applied Biomaterials, 93(2), 394-400.

Filho, H.N. et al., 2014. 'Autogenous bone grafts contamination after exposure to the oral cavity'. Journal of Craniofacial Surgery, 25(2), 412-414.

Madhumathi, K. \& Kumar, T.S.S. 2014. 'Regenerative potential and anti-bacterial activity of tetracycline loaded apatitic nanocarriers for the treatment of periodontitis', Biomedical Materials. IOP Publishing, 9(3), p. 35002.

Peña, C., de la Caba, K., Eceiza, A., Ruseckaite, R. \& Mondragon, I. 2010. 'Enhancing water repellence and mechanical properties of gelatin films by tannin addition'. Bioresource Technology, 101(17), 6836-6842.

Phaechamud, T. \& Darunkaisorn, W. 2016. 'Drug release behavior of polymeric matrix filled in capsule'. Saudi Pharmaceutical Journal, 24(6), 627-634.

Samad, R., Akbar, F.H., Nursyamsi, N. \& Awing, M. 2017. 'Propolis trigona sp. mouthwash efectiveness in lowering anaerobic gramnegative bacteria colonies', in Health Science International Conference (HSIC 2017), Atlantis Press., pp. 181-187 doi:

Scatolini, A.M., Pugine, S.M.P., De Oliveira Vercik, L.C., De Melo, M.P., \& Da Silva Rigo, E.C. 2018. 'Evaluation of the antimicrobial activity and cytotoxic effect of hydroxyapatite containing Brazilian propolis'. Biomedical Materials (Bristol), 13(2), 1-31.

Suryono, S., Hasmy, N.S., Pertiwi, T.L. \& Benyamin, B. 2017. 'Propolis 10\%-gel as a topical drug candidate on gingivitis'. International Journal of Medicine and Pharmacy, 5(2), 1217.

Zohery, A.A., Meshri, S.M., Madi, M.I., Abd El Rehim, S.S. \& Nour, Z.M. 2018. 'Egyptian propolis compared to nanohydroxyapatite graft in the treatment of Class II furcation defects in dogs'. Journal of Periodontology, 89(11), 1340-1350. 